\title{
Identification of Antioxidant compounds in red raspberry (Rubus Idaeus) Fruit in Kurdistan region (north Iraq)
}

\author{
${ }^{1}$ Dalia A. Abdul, ${ }^{2}$ Srwa N. Majeed \\ ${ }^{1,2}$ Department of Chemistry, School of Science, Faculty of Science\& Science education, University of \\ Sulaimani
}

\begin{abstract}
The six different antioxidant compounds in red raspberry(Rubus ideaus) Fruit which grows in sulaimani city- Kurdistan region -north Iraq (season 2011) were detected by using HPLC technique including neoxanthin ,lutein, anthocynin, ellagitanins,B-carotene and violaxanthin the amount of them were $21.6060 \mathrm{mg} / \mathrm{ml}, 110.8226 \mathrm{mg} / \mathrm{ml}, 291.7407 \mathrm{mg} / \mathrm{ml}, 205.2504 \mathrm{mg} / \mathrm{ml}, 261.6247 \mathrm{mg} / \mathrm{ml}$ and $129.3089 \mathrm{mg} / \mathrm{ml} \mathrm{respectively}$ Keywords: Antioxidant, red raspberry, HPLC analysis, lutein, anthocyanin, B-carotene, violaxanthin, neoxanthin, ellagitanins
\end{abstract}

\section{Introduction:}

Red raspberry is a plant which stand about 6 feet tall. It is often found growing wild in hedges. It may be vining or shrubby but tends to grown in thickets, it belongs to the genus(Rubus),the genus Rubus is a member of the rose family (Rosaceae).It is cultivated and grows wild in sulaimani city- Iraq(1).A local name of red raspberry fruit in Kurdish is totirk(1).

Antioxidant substances are phytochemicals, which are found naturally in plants that help fight disease in humans, these antioxidant delay aging and prevent disease by destroying free radicals from harming your DNA and causing cellular damage and death(2) .Toxicity of these compounds and the growing interest in safe nutritional additives by consumers has created the necessity to identify natural and safe source for food antioxidants(3) .Raspberries are an important commercial fruit crop. Widely grown in all temperate regions of the world (4.)Raspberries contain significant amount of poly phenol antioxidants such as anthocyanin pigments linked to potential health protection against several human diseases (5).The aggregate fruit structure contributes to its' nutritional value as it increases the proportion of dietary fiber, placing it among plant foods with the highest fiber contents known up $20 \%$ fiber per total weight(6). Raspberry are a rich source of vitamin C with $30 \mathrm{mg}$ per serving of 1 cup (about 50\% daily value),manganese(about60\% daily value),content of B vitamins 13 ,folic acid,magnesium,copper and iron ate considerable in raspberries(6).Raspberries rank near the top of all fruit for antioxidant strength,particulary due to their denes contents of ellagic acid (from ellagitannins),and anthocyanins.It has an ORAC value of about 4900 per 100 gram(7).Neoxanthin is a carotenoid and xanthophylls in plants,it is intermediate in the biosynthesis of the plant hormone abscisic acid .It is produced from violaxanthin by the action of neoxanthin synthase(8).lutein from Latin luteus meaning yellow is xanthophylls and one of 600 known naturally occurring carotenoids. It is synthesized only by plants and like other xanthophylls is found in high quantities in green leafy vegetables such as spinach and kale(9).It is antioxidant ,which belongs to the carotenoid family. Although lutein is not categorized as a vitamin ,dietary lutein is believed to be an essential nutrient for normal vision,studies have also indicated that lutein improves heart health, reduces diabetes and anti-cancer properties(10). Anthocyanins belong to group of flavonoids polyphenolic molecules they can be found in tissues of plants, including leaves, stems ,roots, flowers and fruits. Studies have shown that anthocyanin may act as anti-cancer by inhibit promotion and progression of tumor cells by stopping the growth of pre-malignant cells(11) results demonstrate the strong antiproliferative activity of violaxanthin on one human mammary cancer cell line, and suggest that studying the pharmacology of violaxanthin and pharmacomodulated derivatives on cancer cells may allow potent antiproliferative drugs to be obtained(12).

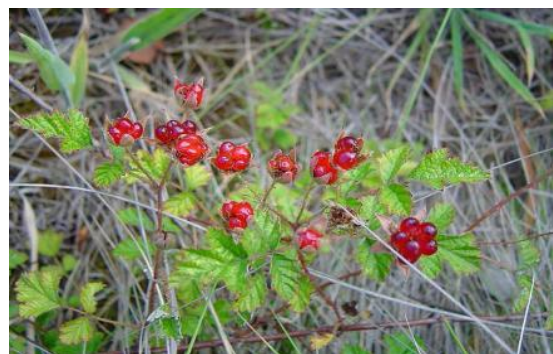

Fig(1) Red raspberry (Rubus Idaeus) fruit 


\section{Material and methods}

Red raspberry fruit was harvested by hand in its optimum state for two consecutive seasons in 2011 in Sulaimani city -Iraq. After a morphological and chemical characterization, the sample was prepared for determination of antioxidant compounds,elemental analysis and protein determination.

\section{1-Extraction Procedure of antioxidant compounds(13)}

Active ingredient were extracted according to the procedure reported by Lakshimin anayana etal (13)which were modified according to our fast FLC fast liquid chromatographic separation which briefly described as follow ; the sample powder $5 \mathrm{mg}$ were extracted with ice -cold acetone until the sample become colorless (final volume $100 \mathrm{ml}$ ), the crude extract $(50 \mathrm{ml}$ )were taken in separating funnel ,100 $\mathrm{ml}$ of the petroleum ether added after mixing well, the upper layer were separated ,the extract were repeated three times. Total volume $(200 \mathrm{ml})$ the extract was dried over anhydrous sodium sulphate $20 \mathrm{mg}$ and filtered through whatmann no.1 Filter paper. The filtrate were evaporated to dryness in rotary evaporator (Buchi Switzerland ) at $30 \mathrm{C} 0$ and re-dissolved in known volume of hexane and aliquot of $20 \mu / \mathrm{ml}$ were used for HPLC analysis.

\section{2- Determination of element concentration}

$10 \mathrm{gm}$ of sample was weighted in to a porcelain crucible, placed in a muffle furnace temperature was increased to $600{ }^{\circ} \mathrm{C}$ and held at the temperature for $6 \mathrm{~h}$., the sample was removed from the furnace and weighted, the determine percentage of ash for sample was $(0.2) \%$. The residual ash was dissolved in 1:1 nitric acid filtered and the volume was completed to $(100 \mathrm{ml})$ distilled water, the solution was injected to OES-ICP Perkin Elmer 2100 for determine

\section{3- Determination of protein by Micro Kjeldhal (14) \\ Preparation of solution}

A- 10 N NaoH:- (40g) of NaoH was dissolved in $100 \mathrm{ml}$ distilled water

B-Boric acid solution : Dry boric acid $(2 \mathrm{~g})$ was dissolved in $(100 \mathrm{ml})$ of distilled water in a volumetric flask $(100 \mathrm{ml})$ and mixed well

C-Mixed indicator :- Methyl red indicator(0.016g)and bromocresol green indicator $(0.099) \mathrm{g}$ were dissolved in absolute ethanol $(100 \mathrm{ml})$ and mixed well

D-(2ml)of solution in step $\mathbf{C}$ was added to the solution in step $\mathbf{B}$, the volume completed with distilled water and the $\mathrm{PH}$ of the solution was adjusted to (5) exactly

\section{Procedure}

According to the Schuffelen and co-workers (14) the raspberry fruit ( rubs idea) $(0.5 \mathrm{~g})$ was digested by digestion system with concentrated Sulfuric acid $(10 \mathrm{ml})$ and hydrogen peroxide $10 \mathrm{ml}$, until a clear solution was obtained, then the volume was completed with distilled water to $100 \mathrm{ml}, 10 \mathrm{ml}$ of digested was transferred to a micro Kjeldahi system, solution number $\mathbf{A} 10 \mathrm{ml}$ was added and the liberated ammonia was combined to a conical flask that contain $25 \mathrm{ml}$ solution number $\mathbf{D}$. The colour was changed to green . The latter solution was titrated with Sulfuric acid $0.0462 \mathrm{~N}$

The total nitrogen and protein percentage were calculated according to equation (1) and (2)

$\% \mathrm{~N}=(\mathrm{ml}$ acid of sample $-\mathrm{ml}$ acid of blank $) \times 0.05 \times 100 \times 100 \times 14 / \mathrm{wt}$ of sample x10x1000 ----1

$\%$ protein $=\% \mathrm{Nx}$ protein Coefficient $-2$

\section{Result and discussion}

The HPLC analysis of antioxidant compounds in red raspberry fruit are present in table(1)fig(2), from the result six different antioxidant compounds are indicated includes violxanthin ,lutein, anthocynins , ellagitanins and B-carotene . red raspberry fruit contain high amount of anthocyanins $291.7407 \%, \beta$-carotein $261.6247 \%$,ellagitanins $205.2504 \%$,violanthin $129.3089 \%$, lutein $110.8226 \%$ and neoxanthin $21.6060 \%$.

Elemental analysis have been done by inductive couple plasma(ICP) techniques (OES-ICP Perkin Elmer 2100) for red raspberry fruit table(2) which a high amount of K,P,Ca and Mg elements have been detected.

The percentage of protein by Micro Kjeldhal method in this fruit is 1.2 per 100 gram and glucose, sucrose and fructose was determined

\section{Conclusion}

The red raspberry fruit in sulaimani city -Kurdistan region- Iraq is a rich source antioxidant compounds like violxanthin, lutein, anthocynins, ellagitanins and B-carotene. The content of anthocyanin is very high in the raspberry fruit, all these components are powerful anti-oxidants and are beneficial in preventing cardiovascular diseases like Angina, arteriosclerosis and present of anthocyanin,ellagitanins can reduce LDL oxidation. Also Research on anthocyanins also shows that they reduce the coagulation of blood platelets, inhibiting formation of blood clots involved in stroke, pulmonary embolism, peripheral vascular 
disease and heart attack, promote higher levels of " good" cholesterol (HDL), and inhibit oxidation of " bad" cholesterol (LDL).

Raspberry fruit is loaded with trace elements such as potassium, zinc, iron, copper, manganese, etc. These trace elements are important constituents of various enzymes.

\section{Acknowledgement}

We are very much indebted to the department of chemistry, faculty of science and science education, University of Sulaimani for providing the facilities ,encouragement and financial support during the investigation .Also thanks due to the University of Baghdad for obtaining HPLC technique for identification of antioxidant compounds in red raspberry

\begin{tabular}{|l|l|l|l|l|l|l|l|}
\hline no & subjects & Rt/minute & area/standard & df & area/sample & conce. $\mu$ g/ml & $\begin{array}{l}\text { conce. of } \\
\text { sample }\end{array}$ \\
\hline $\mathbf{1}$ & Neoxanthin & 1.15 & 12014 & 3 & 3461 & 25 & 21.6060 \\
\hline $\mathbf{2}$ & Violaxanthin & 2.24 & 15909 & 3 & 27429 & 25 & 129.3089 \\
\hline $\mathbf{3}$ & Lutien & 3.47 & 14777 & 3 & 21835 & 25 & 110.8226 \\
\hline $\mathbf{4}$ & $\boldsymbol{\beta}$-carotene & 4.47 & 11996 & 3 & 41846 & 25 & 261.6247 \\
\hline $\mathbf{5}$ & anthocyanins & 5.31 & 12486 & 3 & 48569 & 25 & 291.7407 \\
\hline $\mathbf{6}$ & ellagitanins & 6.46 & 15756 & 3 & 43119 & 25 & 205.2504 \\
\hline
\end{tabular}

Table (1) antioxidant compounds in red raspberry fruit

\begin{tabular}{|l|l|l|}
\hline mineral & units & Value per 100gm \\
\hline $\mathbf{C a}$ & $\mathrm{mg}$ & 20 \\
\hline $\mathbf{F e}$ & $\mathrm{mg}$ & 0.5 \\
\hline $\mathbf{M g}$ & $\mathrm{mg}$ & 21 \\
\hline $\mathbf{P}$ & $\mathrm{mg}$ & 24 \\
\hline $\mathbf{K}$ & $\mathrm{mg}$ & 140 \\
\hline $\mathbf{N a}$ & $\mathrm{mg}$ & 1 \\
\hline $\mathbf{Z n}$ & $\mathrm{mg}$ & 0.40 \\
\hline $\mathbf{C u}$ & $\mathrm{mg}$ & 0.01 \\
\hline $\mathbf{M n}$ & $\mathrm{mg}$ & 0.52 \\
\hline $\mathbf{S e}$ & $\mathrm{mg}$ & 0.20 \\
\hline
\end{tabular}

Table(2) elemental analysis of red raspberry fruit

\begin{tabular}{|l|l|}
\hline Protein & 1.2 per 100 gram \\
\hline Sucrose & 0.2 per 100 gram \\
\hline Glucose & 1.5 per 100 gram \\
\hline Fructose & 2.5 per 100 gram \\
\hline Lactose & 0 per 100 gram \\
\hline Maltose & 0 per 100 gram \\
\hline Galactose & 0 per 100 gram \\
\hline
\end{tabular}

Table(3) protein and sugars content In red raspberry fruit

Fig(2) Chemical structure of antioxidant compounds in red raspberry fruit

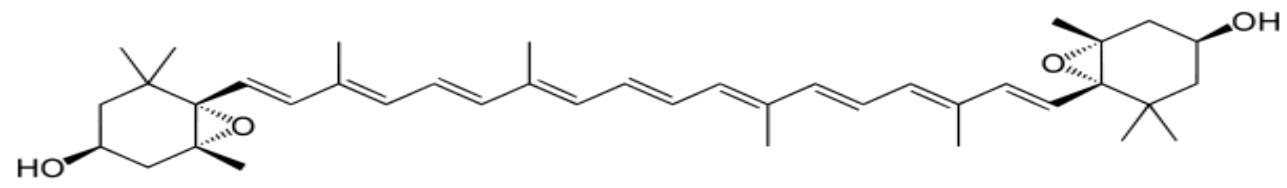




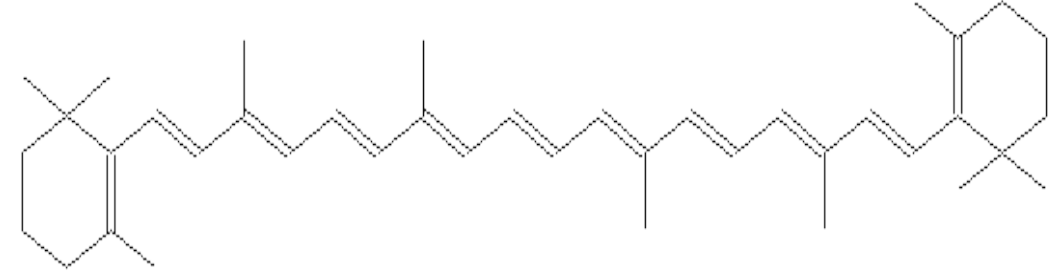

$\beta$-carotene

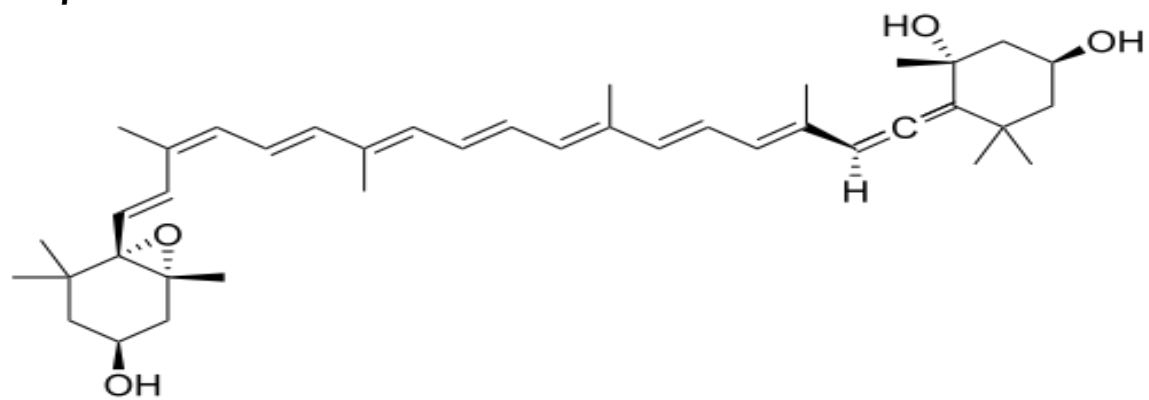

Neoxanthin

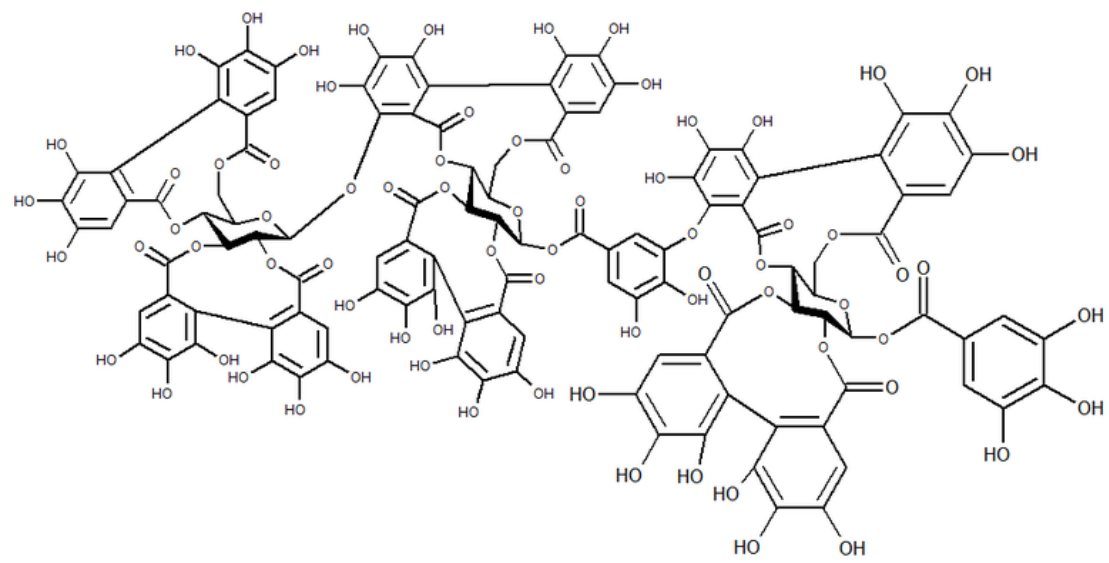

Ellagitannin

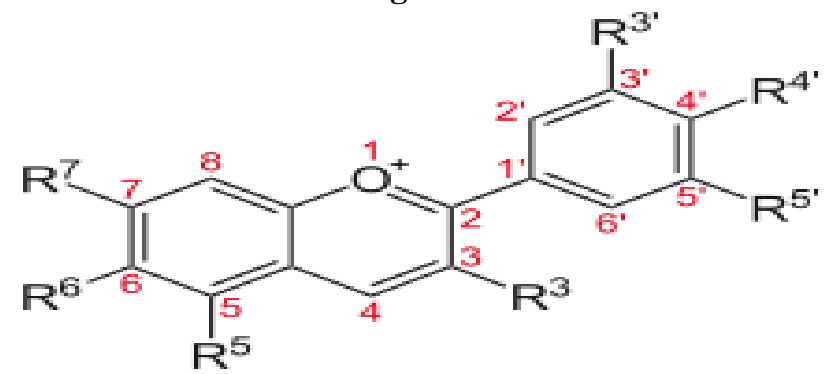

Anthocyanins

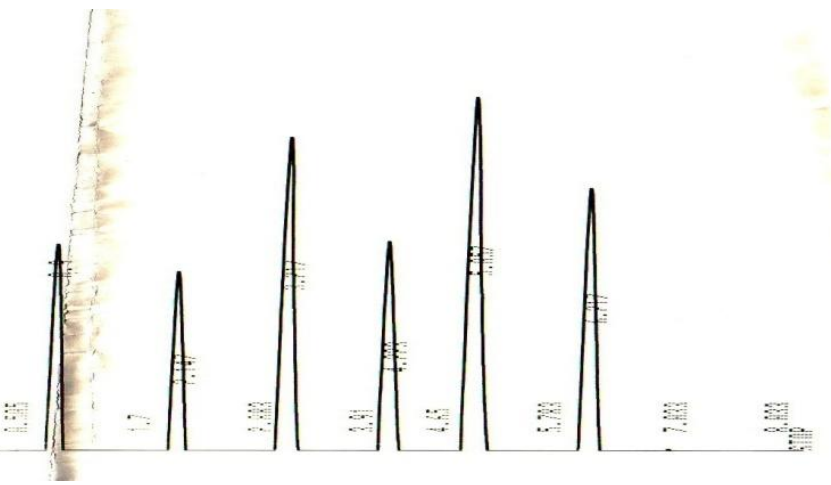

Fig(3):HPLC chromatograms of a mixture of authentic standards of antioxidant compounds 


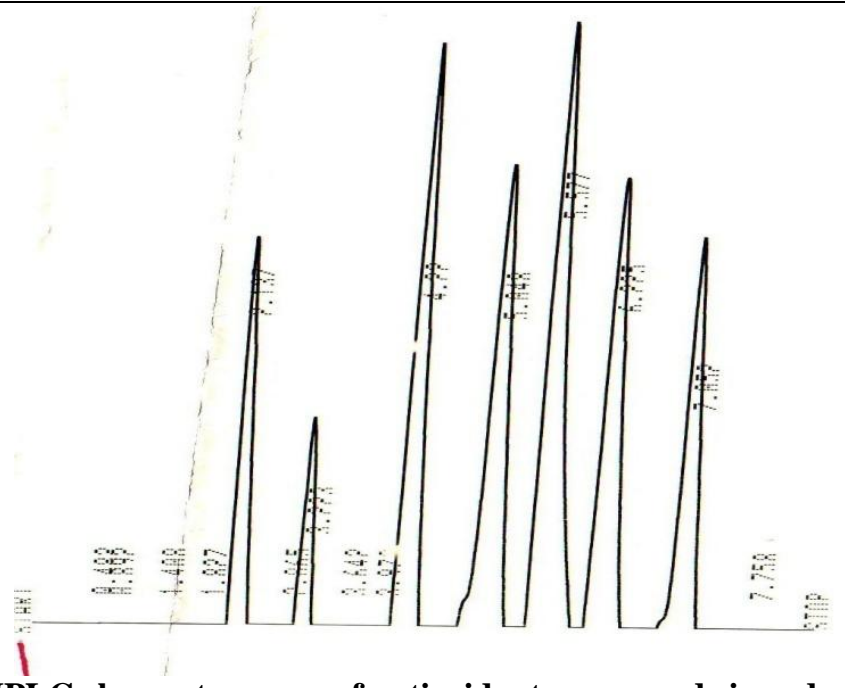

Fig(4):HPLC chromatograms of antioxidant compounds in red raspberry fruit

\section{Reference}

[1] H.I chakravarty, and Ali-Al-rawi medicinal plant of Iraq . $2^{\text {nd }}$ ed , ministry of Agriculture ,Baghdad . 1 (1964)

[2] Prescription for nutritional Healing, Phyllis Blach , 2003 University of Maryland, Medical center

[3] Ajila . C.M , Naidu ,K.A, BHAT .S.G and prasada Raq, U.J.S (2007) Bioactive compounds and antioxidant potential of peel extract ,food chemistry, vol 105 , No3 , p . 982-988

[4] Strick B.C Growing Raspberry in your home garden Growing small fruits Oregon state University Extension service retrived 18 August 2011

[5] Jornal of Agricultural and food chemistry presents research from the 2007 international Berry Health benefits symposium Journal of Agricultural and food chemistry ACS publications ,February 2008

[6] Worlds healthiest Food in- depth nutrient profile for raspberries

[7] Wux ,Beecher GR. Holden JM Haytowiz BD (June 2004) Antioxidant and antiproliferative activities of raspberries. J.Agric. food chem. 50 (10) 2926- 2930

[8] Bouvier,Florence ,Dhorfingue,Alain,Backhaus, Ralph A. 2000 (Identifcation of neoxanthin synthase as carotenoid cycles paralog) European Journal of Biochemistry 267 (21) 6346- 6352

[9] Merrian-Webster on line Dictionary, OED

[10] Niizu, P.Y,Delia B,Rodriguez - Amaya 2005 (flowers and Leaves of Tropaeolum majus I as rich source of Lutein ) Journal of food science 70(9) :S 605- S 609

[11] Phyto chemicals received from www. Yahoo.com

[12] Antiproliferative Activity of Violaxanthin Isolated from Bioguided Fractionation of Dunaliella tertiolecta Extracts, Mar. Drugs 2011, 9, 819-831

[13] LakShminaraynna R.Raja etal (2005) determination of total carotenoids in few Indian leavy vegetable by HPLC. J.Science and technology, 53,2838-2842

[14] N.Schuffelene .J.Agric.Sci.9, 2, 1961 